\title{
Effect of structural character of gold nanoparticles in nanofluid on heat pipe thermal performance
}

\author{
C.Y. Tsai ${ }^{\text {a }}$, H.T. Chien ${ }^{\text {a }}$, P.P. Ding ${ }^{\text {b }}$, B. Chan ${ }^{\text {c }}$, T.Y. Luh ${ }^{\text {d }}$, P.H. Chen ${ }^{\text {a,* }}$ \\ ${ }^{a}$ Thermal MEMS Laboratory, Mechanical Engineering Department, National Taiwan University, No. 1, Roosevelt Road Sec. 4, Taipei 10617, Taiwan, ROC \\ ${ }^{\mathrm{b}}$ Asia Vital Components Co., Ltd., Taipei 242, Taiwan, ROC \\ ${ }^{\mathrm{c}}$ Institute of Chemistry, Academia Sinica, Nankang, Taipei 115, Taiwan, ROC \\ ${ }^{\mathrm{d}}$ Department of Chemistry, National Taiwan University, Taipei 10617, Taiwan, ROC
}

Received 14 July 2003; accepted 2 October 2003

\begin{abstract}
Nanofluid is employed as working medium for conventional circular heat pipe. The nanofluid used in the present study is an aqueous solution of various-sized gold nanoparticles. The thermal resistance of heat pipe with nanofluid or with DI water was measured. The heat pipe was designed as a heat spreader for CPU in a notebook or a desktop PC. At a same charge volume, there is a significant reduction in thermal resistance of heat pipe with nanofluid as compared with DI water. The measured results also show that the thermal resistance of a vertical meshed heat pipe varies with the size of gold nanoparticles.
\end{abstract}

(C) 2003 Elsevier B.V. All rights reserved.

Keywords: Gold nanoparticle; Nanofluid; Tannic acid; Trisodium citrate; Heat pipe; Thermal resistance

\section{Introduction}

It has been demonstrated that suspension of particles has a great potential in improving the heat management ability of fluids [1]. Particles smaller than $100 \mathrm{~nm}$ exhibit properties different from those of conventional solid, thus they have a great potential in heat transfer enhancement [2-4]. Nanoscale materials have received a great deal of attention due to their size- and shape-dependent thermodynamic properties $[5,6]$. Controlling the size and shape of nanomaterials is the major challenge in this field, especially in practical applications such as heat convection and thermal transfer. The thermal conductivity and convective heat transfer of a number of nanomaterials as substitutes to water and ethylene glycol have been studied [7]. However, the applications of metal nanoparticles in heat pipe have not been studied yet. Heat pipes can be used to enhance heat transfer due to the phase change of coolant. They have wide applications in domestic and industrial sectors [8-10]. Fig. 1 shows a typical heat pipe [11]. In general, a commercially

\footnotetext{
* Corresponding author. Tel.: +886-2-23670781; fax: +886-223670781/23631755

E-mail address: phchen@ntu.edu.tw (P.H. Chen).
}

available heat pipe is made of copper with a length of 170 $\mathrm{mm}$ with an outer diameter of $6 \mathrm{~mm}$. In Fig. 1, the evaporator at which heat is absorbed is shown at the right end; the middle section is the adiabatic section; and the left section is the condenser at which heat is rejected out of the structure. Water condensation occurs in the condenser. The condensed water penetrates a mesh wick structure and returned via the inside wall of the pipe. There have been numerous works concerning the use of DI water as the working fluid in a heat pipe. In the present study, a nanofluid of aqueous gold nanoparticles solution is studied for its application in heat pipe.

\section{Experiment}

Monodispersed gold nanoparticles were prepared by the reduction of aqueous hydrogen tetrachloroaurate $\left(\mathrm{HAuCl}_{4}\right.$, Aldrich Chemical) with trisodium citrate and tannic acid (Aldrich Chemical) using a standard procedure [12]. In order to obtain particles of different sizes, various concentrations of tannic acid, trisodium citrate and hydrogen tetrachloroaurat should be used [12]. Different concentrations of materials for each synthesis condition were 


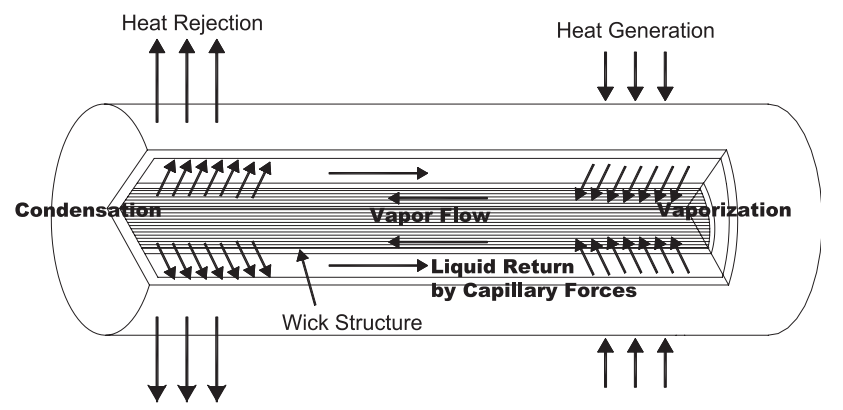

Fig. 1. A schematic view of main heat transfer regions of the heat pipe.

obtained by changing the quantities of initially prepared solutions of $1 \%(\mathrm{w} / \mathrm{v}) \mathrm{HAuCl}_{4}$ solution, $1 \%(\mathrm{w} / \mathrm{v})$ trisodium citrate solution, $1 \%(\mathrm{w} / \mathrm{v})$ tannic acid solution and $2.5 \mathrm{mM}$ potassium carbonate solution. The quantities used for synthesis at each condition are listed in Table 1. Note that both tannic acid solution and potassium carbonate have the same quantity for every synthesis condition. Besides, the difference in concentration of potassium carbonate does not change the size of gold nanoparticles [12]. The final solution is prepared by adding water up to a total volume of $150 \mathrm{ml}$. As the tetrachloroaurate acid solution was heated to $60{ }^{\circ} \mathrm{C}$, the reducing agent solution (a mixture of trisodium citrate, tannic acid and potassium carbonate) were rapidly added with stirring. After an initial color change, the solution was heated to boiling for 5-10 min. The UV-vis absorption of the nanoparticle solutions was measured with a Hitachi U3310 UV-vis spectrometer. High-resolution transmission electronic micrograph (HRTEM, Hitachi H-7000) was used to determine the size of gold nanoparticles.

The diameter and length of copper tube were 6 and 170 $\mathrm{mm}$, respectively. A 200 mesh screen was distributed on the inner tube. The system shown in Fig. 2 is used for thermal performance measurement of heat pipe. The local temperature on the heat pipe was measured by nine isolated type-T thermocouples. Three thermocouples were attached to the evaporator, and three were evenly attached to the condenser section. The length of evaporator section and condenser section is 30 and $50 \mathrm{~mm}$, respectively. All thermocouples were calibrated against a quartz thermometer. The uncertainty in temperature measurements was $\pm 0.1{ }^{\circ} \mathrm{C}$.

Two heater bars (maximum $90 \mathrm{~W}$ ) were used as heat source in the measurements. Thus, the heating load $(Q)$ and the temperature difference $\left(\mathrm{d} T=T_{\text {evaporator }}-T_{\text {condenser }}\right)$ were

Table 1

Volumes of materials used in different synthesis conditions

\begin{tabular}{llll}
\hline Condition & $\mathrm{Na}_{3}$ citrate $(\mathrm{ml})$ & Tannic acid $(\mathrm{ml})$ & $\mathrm{HAuCl}_{4}(\mathrm{ml})$ \\
\hline $\mathrm{A}$ & 0.2 & 2.5 & 3 \\
$\mathrm{~B}$ & 0.2 & 5 & 6 \\
$\mathrm{C}$ & 3 & 0.1 & 1 \\
E & 3 & 2.5 & 6 \\
$\mathrm{G}$ & 3 & 0.1 & 3 \\
\hline
\end{tabular}

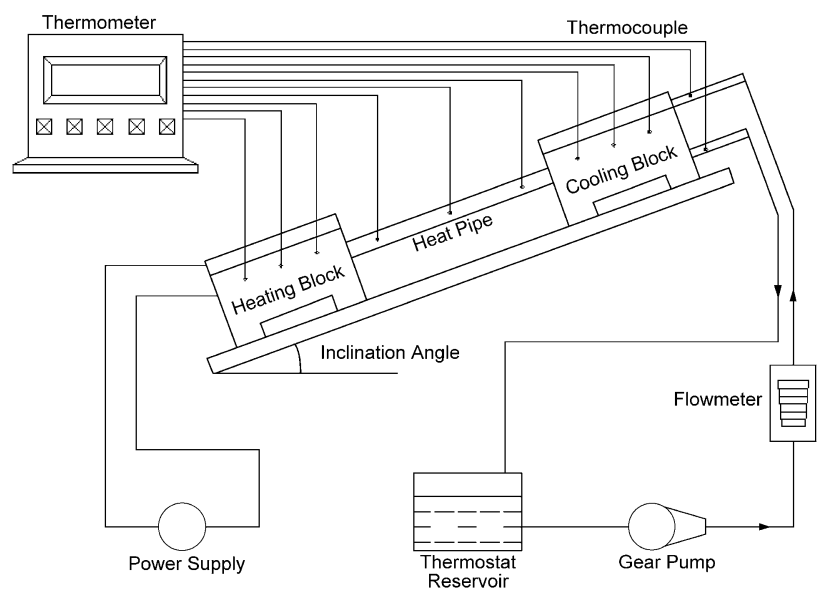

Fig. 2. A schematic view of the system for measuring the thermal performance of heat pipe with nanofluid.

measured, and the thermal resistance $(R)$ was calculated by the equation, $R=\mathrm{d} T / Q$. For the present study, the heat pipe was vertically fixed during measurement. In addition to $\mathrm{d} T$, we have also calculated the temperature differences, $\mathrm{d} T_{\mathrm{e}}=$ $T_{\text {evaporator }}-T_{\text {adiabatic }}$ and $\mathrm{d} T_{\mathrm{c}}=T_{\text {adiabatic }}-T_{\text {condenser }}$. The thermal resistance from the evaporator section to the adiabatic section, $R_{\text {evap }}$, and the thermal resistance from the adiabatic section to the condenser section, $R_{\text {cond }}$, are caculated by $\mathrm{d} T_{\mathrm{e}} / Q$ and $\mathrm{d} T_{\mathrm{c}} / Q$, respectively.

\section{Results and discussion}

Typical TEM photographs of the gold nanoparticles that were prepared in different conditions (in Table 1) are shown in Fig. 3. The size differences and shape changes of the gold nanoparticles can be observed from Fig. 3A-E. The TEM photographs show that gold nanoparticles prepared by conditions $\mathrm{C}, \mathrm{D}$ and $\mathrm{E}$ are smaller than those prepared by conditions A and B. As listed in Table 1, the concentration of trisodium citrate used in conditions $\mathrm{C}, \mathrm{D}, \mathrm{E}$ was 15 times higher than in conditions $\mathrm{A}$ and $\mathrm{B}$. This indicates that an increase in the trisodium citrate concentration causes a size reduction of gold nanoparticles. However, gold nanoparticles prepared in much higher concentration of trisodium citrate do cluster together but not precipitate. Comparing Fig. $3 \mathrm{~A}$ and $\mathrm{B}$, the gold nanoparticles were generally spherical in Fig. $3 \mathrm{~A}$, whereas, with increasing quantities of $\mathrm{HAuCl}_{4}$ and tannic acid, larger particles can be observed in Fig. 3B.

The size distribution of the nanoparticles was shown in Fig. $4 \mathrm{~A}-\mathrm{E}$. The range of nanoparticle size is $2-35 \mathrm{~nm}$ and the peak is $24 \mathrm{~nm}$ for particles prepared by condition A. While the range is $15-75 \mathrm{~nm}$, the peak becomes $40 \mathrm{~nm}$ for particles prepared by condition $\mathrm{B}$, with higher $\mathrm{HAuCl}_{4}$ and tannic acid concentrations in the final solution. The average diameter of nanoparticles, as determined from Fig. 4A and $\mathrm{B}$, are 21.3 and $43.7 \mathrm{~nm}$, respectively. 

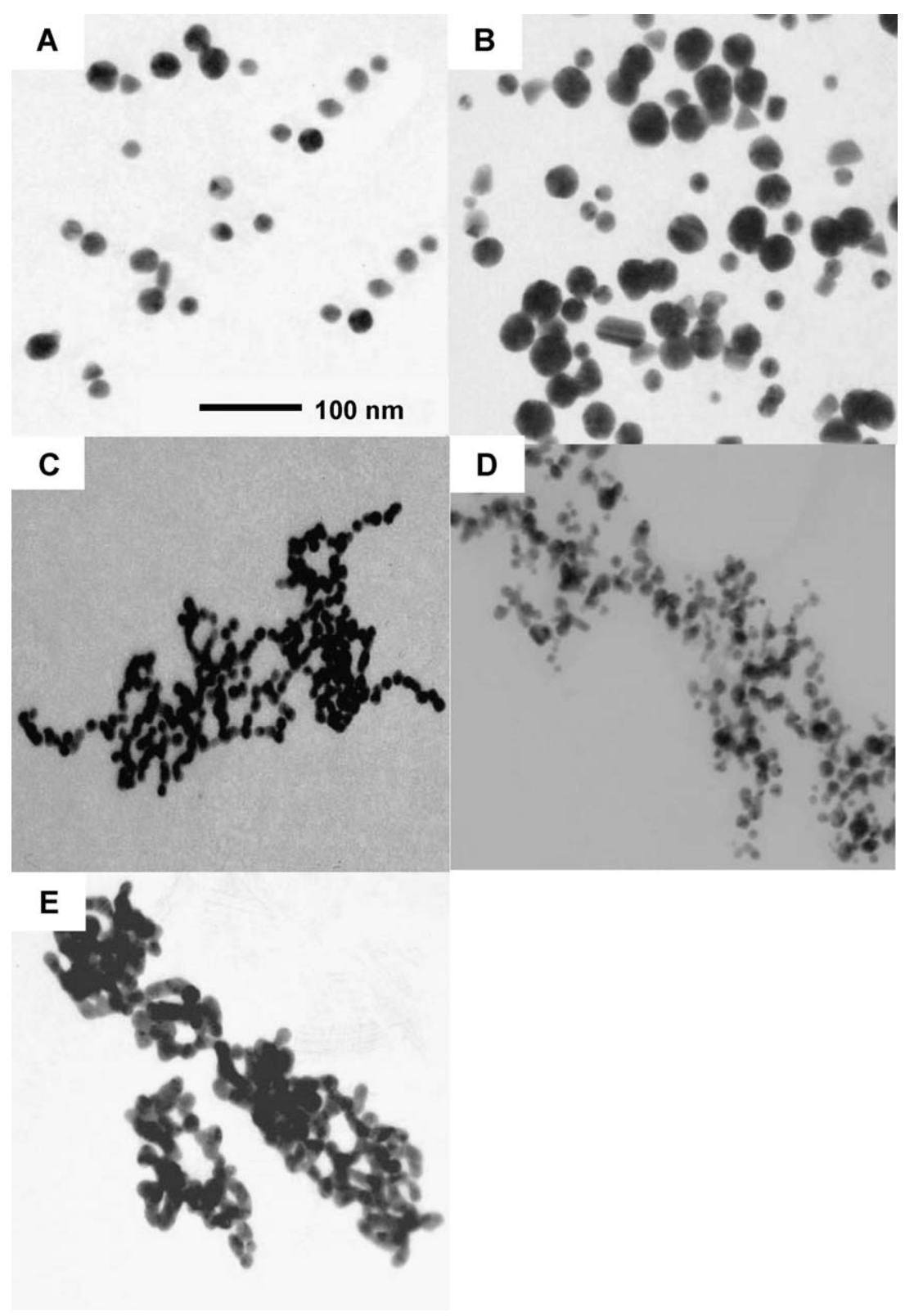

Fig. 3. TEM photographs of gold nanoparticles prepared by different conditions with a magnification of 100000 . Table 1 shows the quantities of each material used in the final aqueous solution for each condition.

With condition $\mathrm{D}$, the particle size ranges from 4 to 11 $\mathrm{nm}$. On the other hand, the particle size becomes larger and ranges from 10 to $20 \mathrm{~nm}$ with a higher $\mathrm{HAuCl}_{4}$ concentration in condition $\mathrm{E}$ as shown in Fig. $4 \mathrm{C}$ and $\mathrm{E}$. However, by increasing the quantity of tannic acid and $\mathrm{HAuCl}_{4}$ simultaneously in condition $\mathrm{D}$, the range of particle size changes from 2 to $16 \mathrm{~nm}$. The average diameter of nanoparticles, as determined from Fig. 4C,D and E, are 8, 9.3 and $15.6 \mathrm{~nm}$, respectively. By increasing $\mathrm{HAuCl}_{4}$ concentration alone, the average particle size increases from $8 \mathrm{~nm}$ for condition $\mathrm{C}$ to $15.6 \mathrm{~nm}$ for condition E. In addition, the aggregation of nanoparticles becomes more serious at higher $\mathrm{HAuCl}_{4}$ concentration.
Similar to the case with lower trisodium citrate concentration, the size of gold nanoparticles increases with an increase in both concentrations of tannic acid and $\mathrm{HAuCl}_{4}$ as illustrated in Fig. 4C and D. However, the average particle size reduces from $15.6 \mathrm{~nm}$ for condition $\mathrm{E}$ to 9.3 $\mathrm{nm}$ for condition $\mathrm{D}$ if both concentrations of tannic acid and $\mathrm{HAuCl}_{4}$ increase simultaneously. It indicates that higher tannic acid concentration can prevent the formation of larger gold nanoparticle.

A local absorption peak value in the UV-vis spectra of gold nanoparticle solution prepared by condition A is 528 $\mathrm{nm}$, while the peak value for conditions $\mathrm{B}, \mathrm{C}, \mathrm{D}$ and $\mathrm{E}$ is 530.5, 568.5, 647 and $721.5 \mathrm{~nm}$, respectively. According to 

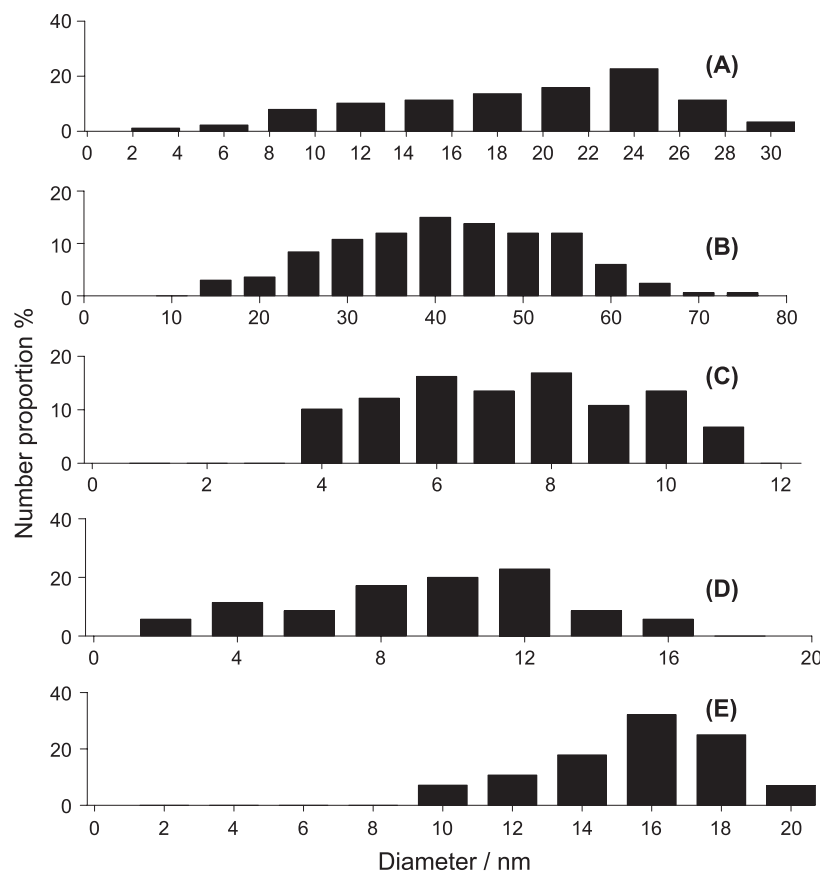

Fig. 4. Statistical size distribution of the gold nanoparticles obtained from TEM photographs for different conditions.

Mie's theory, the surface plasmon absorption and the plasmon bandwith are size-dependent with the metallic particles in the solution. Therefore, this peak value represents the size at which the gold nanoparticle most populates in the solution. In addition, the bandwidth decreases with increasing the particle size for particles smaller than $20 \mathrm{~nm}$ [13]. Contrarily, for particles larger than $20 \mathrm{~nm}$, the bandwidth of the surface plasmon band increases with the particle size $[14,15]$. The local peak in the UV-vis spectra shifts towards longer wavelength as the particle size increases. As observed in Fig. $3 \mathrm{~A}-\mathrm{E}$, it is believed that the smaller particles have eventually linked in the solution, although a solution of higher trisodium citrate concentration was used to form the smaller particles. Consequently, the surface plasmon absorption in the UV-vis spectra for conditions $\mathrm{C}, \mathrm{D}, \mathrm{E}$ not only has larger peak value but also has broader band as compared with that for conditions $\mathrm{A}$ and $\mathrm{B}$. It is due to the reason that the aggregation of particles results in a higher value in the plasmon absorption maximum and a broader band of plasmon absorption by the change in particle dispersion effect. This phenomenon can be confirmed by the experiments of Storhoff et al. [16]. The DNAmodified gold nanoparticles were linked together through

Table 2

Measured values of $R_{\text {evap }}$ and $R_{\text {cond }}$ in different synthesis conditions

\begin{tabular}{lll}
\hline Working Fluid & $R_{\text {evap }}\left({ }^{\circ} \mathrm{C} / \mathrm{W}\right)$ & $R_{\text {cond }}\left({ }^{\circ} \mathrm{C} / \mathrm{W}\right)$ \\
\hline DI water & 0.126 & 0.144 \\
E & 0.085 & 0.13 \\
D & 0.08 & 0.126 \\
C & 0.066 & 0.134 \\
A & 0.055 & 0.115 \\
\hline
\end{tabular}

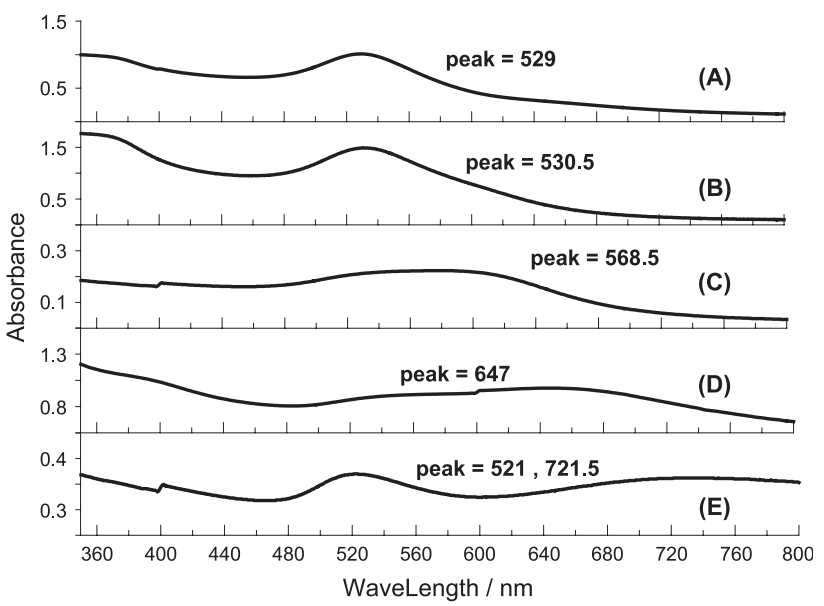

Fig. 5. The surface plasmon absorption of gold nanoparticles. The UV-vis absorption spectra of gold nanoparticles in aqueous solutions prepared by different conditions.

oligonucleotide hybridization in their work. A higher peak value and a broader band could be observed in their UV-vis spectra after the particles were linked together in the solution.

Fig. 6 shows the effect of nanoparticle size on the thermal performance of the meshed heat pipe. A 200 mesh wire screen is used in the tested heat pipe. Note that the data for experiments with nanoparticles prepared by condition $\mathrm{B}$ was not showed in the results because the nanoparticles of this solution underwent irreversible precipitated 6 days later. The thermal resistance of heat pipe containing nanoparticle solution (the so-called nanofluid) prepared by conditions A, $\mathrm{C}, \mathrm{D}$ and $\mathrm{E}$ is $0.17,0.2,0.206$ and $0.215^{\circ} \mathrm{C} / \mathrm{W}$, respectively. Using nanofluid prepared by condition $\mathrm{A}$, the thermal

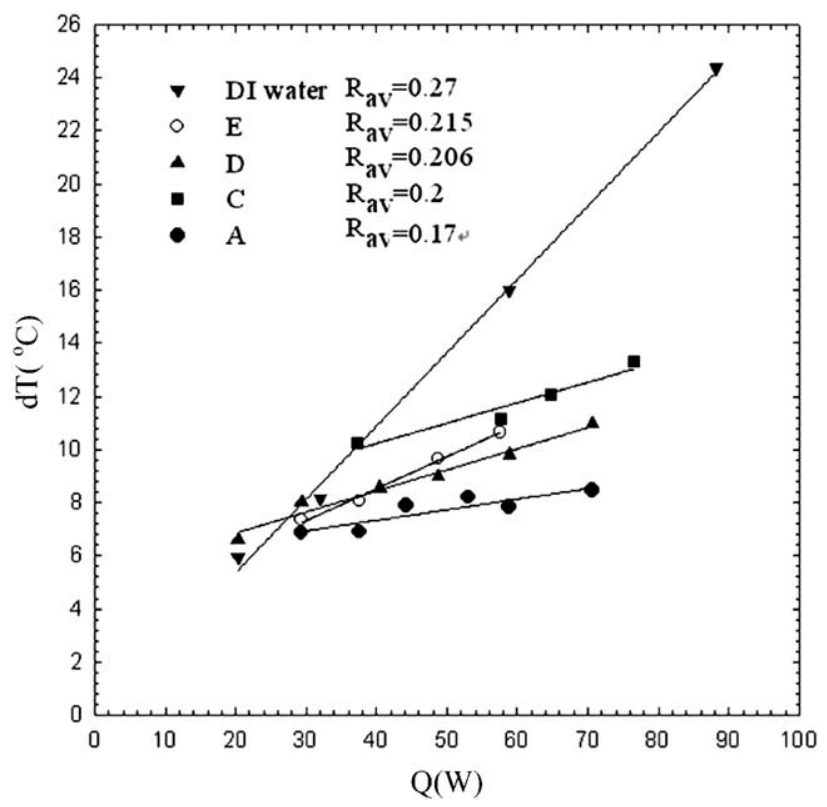

Fig. 6. Measured values of thermal resistance of heat pipe with nanofluid prepared by different conditions. 
resistance of heat pipe is $37 \%$ lower than that using DI water. Using nanofluid prepared by conditions C, D and E, the measured thermal resistances are also lower than that using DI water, and the percentage in reducing thermal resistance of heat pipe is $25 \%, 23 \%$ and $20 \%$, respectively.

Table 2 presents the list of values of $R_{\text {evap }}$ and $R_{\text {cond }}$ for nanofluids prepared by synthesis conditions of E, D, C and A. From Table 2, the major reduction in thermal resistance of the heat pipe is on the thermal resistance from the evaporator section to the adiabatic section. The value of $R_{\text {evap }}$ in conditions $\mathrm{E}, \mathrm{D}, \mathrm{C}$ and $\mathrm{A}$ is $0.085,0.08$, 0.066 and $0.055{ }^{\circ} \mathrm{C} / \mathrm{W}$, respectively. As compared with the value of $R_{\text {evap }}$ using DI water, the percentage in reduction ranges from $33 \%$ to $56 \%$. This reducing percentage in $R_{\text {evap }}$ is larger than that in $R_{\text {cond. }}$. Only $7 \%$ to $20 \%$ reduction can be observed in $R_{\text {cond }}$ if nanofluid is used in the test heat pipe.

The reason for reducing the thermal resistance of heat pipe can be explained as follows. A major thermal resistance of heat pipe is caused by the formation of vapor bubble at the liquid-solid interface. A larger bubble nucleation size creates a higher thermal resistance that prevents the transfer of heat from the solid surface to the liquid [17]. The suspended nanoparticles tends to bombard the vapor bubble during the bubble formation. Therefore, it is expected that the nucleation size of vapor bubble is much smaller for fluid with suspended nanoparticles than that without them.

A reduction in $R_{\text {cond }}$ can also be observed by replacing DI water with nanofluid in the test heat pipe. This arises from the fact that the suspended nanoparticles in a fluid flow can increase both the thermal conductivity of fluid and convective heat transfer from fluid flow to the wall $[4,18]$.

To explain the effect of suspended particle size in nanofluid on the thermal resistance of heat pipe, the UV-vis spectra is better than the statistical particle size distribution obtained from TEM photos because the particle cluster will move together in the fluid. The peak value in surface plasmon absorption increases from the solution by condition A to the solution by condition $\mathrm{E}$ as shown in Fig. 5A-E. Double peaks in the UV-vis spectra for the solution prepared by condition $\mathrm{E}$ indicates that both monodispersed and aggregated particles exist simultaneously in the solution. The particle size after considering the particle cluster is smallest for nanofluid prepared by condition A, but largest for nanofluid prepared by condition E. It is in agreement with the measured results on the thermal resistance of heat pipe as shown in Fig. 6. However, the average particle sizes prepared for conditions $\mathrm{C}$ to $\mathrm{E}$ are smaller than that for condition A by the statistical particle distribution obtained from TEM photos. Therefore, it is more recommended to use nanofluid with monodispersed nanoparticles as the working medium of heat pipe than that with aggregated nanoparticles despite their smaller particle size.

\section{Conclusion}

Gold nanoparticle of different sizes were prepared by reduction of $\mathrm{HAuCl}_{4}$ with of tetrachloroaurate, trisodium citrate and tannic acid. In the present study, the size of gold nanoparticle was adjusted by changing the amounts tetrachloroaurate, trisodium citrate and tannic acid. Some of the gold particle solution could be used in the application of heat pipes. The circular heat pipe has a length of $170 \mathrm{~mm}$ and an outer diameter of $6 \mathrm{~mm}$. The thermal resistance of circular heat pipe ranges from 0.17 to $0.215{ }^{\circ} \mathrm{C} / \mathrm{W}$ with different nanoparticle solutions. Furthermore, the thermal resistance of the heat pipes with nanoparticle solution is lower than that with DI water. As a result, the higher thermal performances of the new coolant have proved its potential as a substitute for conventional DI water in vertical circular meshed heat pipe.

\section{References}

[1] S.U.S. Choi, in: D.A. Singiner, H.P. Wang (Eds.), Development and Applications of Non-Newtonian Flows, vol. 66, ASME, New York, 1995, p. 99, FED-VOL. 231/MD.

[2] W. Wang, X. Xu, U.S. Choi, J. Thermophys. Heat Transf. 13 (4) (1999).

[3] Y. Xuan, W. Roetzel, Int. J. Heat Mass Transfer 43 (2000) 3701.

[4] B.X. Wang, H. Li, X.F. Peng, J. Therm. Sci. 11 (3) (2002) 214.

[5] Y. Wang, N. Herron, J. Phys. Chem. 95 (1991) 525.

[6] A. Henglein, Top. Curr. Chem. 143 (1998) 113.

[7] Y. Xuan, W. Roetzel, Int. J. Heat Mass Tranfer 43 (2000) 3701.

[8] F.F. Jebrail, M.J. Andrews, Int. J. Energy Res. 21 (1998) 101.

[9] N. Ghaddar, Y. Nasr, Int. J. Energy Res. 22 (1998) 625.

[10] J. Schmalhofer, A. Faghri, Int. J. Heat Mass Tranfer 36 (1993) 201.

[11] G.P. Peterson, An Introduction to Heat Pipes-Modeling, Testing, and Applications, Wiley, New York, 1994.

[12] M.A. Hayat (Ed.), Colloidal Gold: Principles, Methods and Applications, vols. 1 and 2, Academic Press, San Diego, CA, 1989.

[13] U. Kreibig, U. Genzel, Surf. Sci. 156 (1985) 678.

[14] S. Link, A.M. El-Sayed, J. Phys. Chem., B 103 (1990) 8410.

[15] U. Kreibig, M. Vollmer, Optical Properties of Metal Clusters, Springer, Berlin, 1995

[16] J.J. Storhoff, R. Elghanian, R.C. Mucic, C.A. Mirkin, R.L. Letsinger, J. Am. Chem. Soc. 120 (1998) 1959.

[17] J.G. Collier, J.R. Thome, Convective Boiling and Condensation, Clarendon Press, Oxford, 1996.

[18] Y. Xuan, Q. Li, J. Heat Transfer 125 (2003) 151. 